\title{
A CONSTRUÇÃO SOCIORRETÓRICA DA SEÇÃO DE INTRODUÇÃO EM ARTIGOS ACADÊMICOS DE LINGUÍSTICA APLICADA
}

\author{
THE SOCIO-RHETORICAL CONSTRUCTION IN THE \\ INTRODUCTION SECTION OF APPLIED LINGUISTIC \\ RESEARCH ARTICLES
}

\section{Ametista de Pinho Nogueira Silva* Cibele Gadelha Bernardino** Dawton Lima Valentim ${ }^{* *}$}

\section{RESUMO}

Pesquisas em Análise de Gêneros têm se preocupado, cada vez mais, com a relação entre o contexto de realização de um gênero textual e a descrição/explicação de suas funções retóricas e sociais. No âmbito dos gêneros acadêmicos, as variações disciplinares demonstram que um mesmo gênero textual pode ser construído de forma particular por diferentes áreas disciplinares, reforçando a importância das descrições sociorretóricas de tais gêneros. Amparados teoricamente nos postulados de Swales (1990), para a análise de gêneros textuais, e em Hyland (2000), para a compreensão de culturas disciplinares, nossa metodologia recorreu ao modelo sociorretórico CARS (SWALES, 1990) e aos trabalhos de Costa (2015) e Pacheco, Bernardino e Freitas (2018), a fim de descrever sociorretoricamente a seção de Introdução de 30 artigos experimentais da área de Linguística Aplicada. A análise da configuração composicional prototítpica das introduções foi explicada à luz das respostas de 7 membros experientes da área a entrevistas. Como resultado, propomos uma configuração de descrição sociorretórica que registrou a ocorrência de dois movimentos ("Construindo o objeto de pesquisa" e "Indicando a estrutura do artigo") e quatro passos retóricos: "Construindo problematização por meio de contextualização sócio-histórica do objeto", "Construindo problematização em torno do objeto por meio de discussão com literatura prévia", "Apresentando objetivos" e "Apresentando objeto de pesquisa".

Palavras-chave: análise de gêneros; artigo acadêmico; linguística aplicada.

* Universidade Estadual do Ceará, UECE, Ceará, CE, Brasil. Programa de Pós-graduação em Linguística Aplicada. ametista.pinho@aluno.uece.br

Orcid: https://orcid.org/0000-0003-0155-4075

** Universidade Estadual do Ceará, UECE, Ceará, CE, Brasil. Programa de Pós-graduação em Linguística Aplicada. cibele.gadelha@uece.br

Orcid: https://orcid.org/0000-0001-9097-8704

*** Universidade Estadual do Ceará, UECE, Ceará, CE, Brasil. Programa de Pós-graduação em Linguística Aplicada.dawtonlv@gmail.com

Orcid: https://orcid.org/0000-0002-6240-4030 


\section{ABSTRACT}

Research on Genre Analysis has been increasingly concerned with the relationship between the context of a textual genre production and the description / explanation of its rhetorical and social functions. Within the academic genre studies, the disciplinary variations show that the same textual genre can be constructed in a particular way by different disciplinary areas, reinforcing the importance of the socio-rhetorical descriptions of such genres. Based on the postulates of Swales (1990), for the analysis of textual genres, and on Hyland (2000), for an understanding of disciplinary cultures, our methodology resorted to the socio-rhetorical CARS model (SWALES, 1990) and to the works of Costa (2015) and Pacheco, Bernardino and Freitas (2018), in order to describe the Introduction section of 30 empirical research articles in the area of Applied Linguistics. The analysis of the prototypical compositional configuration of the introductions was explained according to the answers of 7 experienced members of the area to the interviews. As a result, we propose a configuration of a sociorhetorical description that registered the occurrence of two moves ("Constructing the object of research" and "Indicating the article structure") and four rhetorical steps: "Constructing problematization of the object through socio-historical contextualization", "Constructing problematization of the object through discussion with previous literature", "Introducing research purpose" and "Introducing research object".

Keywords: genre analysis; research article; applied linguistic.

\section{INTRODUÇÃO}

A inclusão do contexto de produção e circulação de um gênero textual em sua análise foi um dos principais marcos para uma análise de gêneros menos estrutural, ou seja, menos preocupada com a mera descrição de formas textuais e mais voltada para a compreensão das funções sociais desempenhadas no e pelo gênero. No âmbito dos gêneros acadêmicos, esse processo ganhou força com um livro publicado em 1990, pelo linguista britânico John Swales, chamado Genre Analysis: English in Academic and Research Settings. Ao propor um aporte teórico-metodológico para investigações cujo objetivo fosse não só a descrição retórica de gêneros, mas, também, a descrição de seus aspectos sociais, Swales contribuiu para a consolidação dos Estudos Sociorretóricos de Gêneros, nos quais nossa pesquisa se inscreve.

A proposta sociorretórica de Swales (1990) atrelou três conceitos-chave: o de gênero, o de propósito comunicativo e o de comunidade discursiva. Para Swales (1990, p. 9), "os gêneros são propriedades das comunidades discursivas; isto é, os gêneros pertencem às comunidades, não aos indivíduos [...] ou a comunidades de fala mais amplas" (SWALES, 1990, p. 9, tradução nossa'). Assim, um gênero só pode ser compreendido e analisado se seu contexto de realização e seus usuários

1. "Genres are the properties of discourse communities; that is to say, genres belong to discourse communities, not to individuals [...] or to wider speech communities" (SWALES, 1990, p. 9) 
fizerem parte da equação, de modo que o analista possa perceber, entre outros aspectos, as nomenclaturas criadas pelos membros de uma comunidade para seus gêneros, o conjunto de propósitos compartilhados que podem ser realizados e que movimentos retóricos são mais recorrentes na construção desses propósitos na materialidade textual.

Como instrumento de análise de tal proposta, Swales (1990) delineou a Metodologia CARS (Create A Researcb Space), um conjunto de procedimentos metodológicos para a descrição da configuração composicional de unidades informacionais prototípicas em consonância com os objetivos realizados pelos sujeitos sociais ao utilizarem os gêneros. Adaptada para variados contextos de produção textual, inclusive não acadêmicos ou profissionais (cf. BERNARDINO, 2000), a Metodologia CARS contribuiu para o impulsionamento de uma vasta série de investigações em Análise de Gêneros que, inclusive, ampliaram e aprofundaram, por exemplo, a relação entre os próprios contextos de produção e os gêneros textuais ora investigados.

Um desses aprofundamentos é proposto por Hyland (2000), quando, discutindo sobre escrita acadêmica, propõe o conceito de Cultura Disciplinar, entendendo que os processos de produção, circulação e consumo de gêneros textuais acadêmicos estão intrinsecamente conectados a perpetuação, divulgação e transformação de crenças epistêmicas e práticas disciplinares para os e pelos membros das comunidades disciplinares. Para Hyland (2000), culturas disciplinares diferem umas das outras não só em seus campos de conhecimento, mas, também, em dimensões sociais e cognitivas, por meio de seus objetivos, comportamentos sociais, relações de poder e interesses políticos. Dentro de cada cultura, portanto, indivíduos adquirem competências discursivas específicas que os autorizam a participar como membros. Desse modo, membros efetivos tendem a se comunicar por meio de estruturas retóricas próprias de suas disciplinas e têm pouca dificuldade em identificar os principais periódicos, os eventos mais importantes ou os departamentos mais prestigiados de suas áreas.

O entrelaçamento teórico entre as propostas de Swales e Hyland tem demonstrado que analisar dado gênero textual acadêmico implica analisar não só quais movimentos retóricos são mais recorrentes, mas, também, o que representa essa recorrência para determinada comunidade disciplinar, que objetivos são realizados, que crenças epistêmicas são consolidadas, que relações hierárquicas são estabelecidas e assim por diante. Tal entrelaçamento, no âmbito do Grupo 
de Pesquisa em Discurso, Identidade e Letramento Acadêmicos (DILETA) ${ }^{2}$, fundamentou pesquisas que, uma a uma, engendram uma trajetória coletiva de investigação da realização de gêneros acadêmicos por diferentes áreas disciplinares, suas variações, suas convenções. Destacamos, especialmente, os estudos sobre o gênero artigo acadêmico realizados nas áreas de Linguística e Medicina (COSTA, 2015; LIMA, 2015), Nutrição (PACHECO, 2016), Psicologia (ABREU, 2016), Direito (BERNARDINO; VALENTIM, 2016) e História (FREITAS, 2018). A partir desses estudos, é importante destacar que diferentes áreas de conhecimento constroem os gêneros acadêmicos de diferentes maneiras, variando de acordo com aspectos sociais e epistêmicos das disciplinas, considerando os objetivos e as práticas próprios de cada cultura.

Circunscrita no escopo do grupo DILETA, a pesquisa que passamos a relatar teve como objetivo analisar sociorretoricamente 30 introduções de artigos acadêmicos experimentais da área de Linguística Aplicada, explicando a configuração composicional prototípica à luz dos dados obtidos em sete entrevistas feitas a membros experientes da cultura em questão. É oportuno ressaltar que esta pesquisa tem caráter exploratório-descritivo, de modo que os dados obtidos contribuem para a suscitação de aspectos do gênero e da cultura disciplinar em estudo que poderão ser aprofundados em investigações futuras. Para tanto, dividimos este artigo em: 1) aporte teórico; 2) percurso metodológico; 3) análise e discussão dos resultados; e 4) considerações finais.

\section{APORTE TEÓRICO}

A configuração composicional prototípica do gênero artigo acadêmico, quer seja a partir da descrição de seções quer seja em sua totalidade, tem sido objeto de estudo, pelo menos, desde a década de 1980 (cf. BAZERMAN, 1984 apud SWALES, 1990), com mais impulso a partir da década seguinte. Swales (1990), por exemplo, concentrou-se na análise da seção de Introdução de artigos científicos produzidos por diversas áreas de conhecimento, a fim de encontrar um modelo de configuração recorrente. Já Nwogu (1997) analisou a configuração retórica de 15 exemplares do gênero artigo acadêmico experimental produzido por membros da área da Medicina.

2. O grupo é coordenado pela Prof. ${ }^{a}$ Dr. ${ }^{a}$ Cibele Gadelha Bernardino, da Universidade Estadual do Ceará (UECE), e está cadastrado no Diretório de Grupos de Pesquisa no Brasil com o link < dgp. cnpq.br/dgp/espelhogrupo/8874562298758535>. 
Depois da virada para o século XXI, podemos destacar, ainda em torno do gênero artigo científico, as pesquisas de Yang e Allison (2003) e Lim (2006). Yang e Allison (2003) investigaram a configuração das seções de resultados, discussão, conclusão e implicações pedagógicas do gênero artigo acadêmico da área de Linguística Aplicada. Lim (2006) se dedicou a uma unidade retórica do gênero artigo acadêmico até então pouco estudada, a de metodologia, na área de Administração.

No âmbito do Grupo de Pesquisa em Discurso, Identidade e Letramento Acadêmicos - DILETA, como já mencionamos na introdução, uma série de estudos, desde Costa (2015), tem sido desenvolvida tomando a integralidade de seções do gênero artigo acadêmico quando produzido por diferentes áreas. Neste trabalho, que também emerge dessa série de estudos, analisaremos sociorretoricamente 30 introduções de exemplares do gênero artigo científico experimental da área disciplinar de Linguística Aplicada.

O artigo acadêmico é "o gênero textual mais conceituado na divulgação do saber especializado acadêmico" (MOTTA-ROTH; HENDGES, 2010, p. 66), o que reforça seu protagonismo nas práticas disciplinares da maior parte das áreas de conhecimento que constituem o domínio acadêmico. Motta-Roth (2002) afirma que, "ao produzirem e publicarem exemplares desse gênero, os (as) autores (as) buscam construir, frente à comunidade acadêmica, a identidade de um (a) pesquisador (a) capaz de refletir sobre estudos relevantes" (p. 40), construindo uma "participação plena nas atividades da comunidade" (BIASI-RODRIGUES; HEMAIS; ARAÚJO, 2009, p. 24).

Para Silva (1999), a recorrência do uso do artigo científico para a divulgação de estudos na rotina acadêmica pode ser compreendida, também, pela importância de "uma interação constante e dinâmica entre os membros (...) da academia e a necessidade (...) de terem seus trabalhos reconhecidos para efeito de financiamento junto a órgãos de fomento" (p. 40-41). O uso de tal gênero para a divulgação de pesquisas também pode ser justificado pelas características do próprio gênero que permitem descrição do estudo, exposição e avaliação dos resultados e construção de argumentação relevante (MOTTA-ROTH; HENDGES, 2010) através do cumprimento das convenções da comunidade acadêmica (BERNARDINO, VALENTIM, 2016).

Swales (1990) afirma que o gênero artigo acadêmico é recorrentemente constituído por quatro grandes seções: Introdução, Métodos, Resultados e Discussão. A partir da descrição de uma dessas seções, a Introdução, de mais de 100 artigos de variadas áreas, o teórico delineou o Modelo CARS (Create a Research Space), um de nossos instrumentos de investigação, como podemos ver abaixo. 


\section{Quadro 1. Modelo CARS}

\begin{tabular}{|ll|}
\hline MOVIMENTO 1: ESTABELECER O TERRITÓRIO & \\
Passo 1 - Estabelecer a importância da pesquisa. & e/ou \\
Passo 2 - Fazer generalização/ões quanto ao tópico. & e/ou \\
Passo 3 - Revisar a literatura (pesquisas prévias) & \\
MOVIMENTO 2: ESTABELECER O NICHO & \\
Passo 1A - Contra-argumentar & ou \\
Passo 1B - Indicar lacuna/s no conhecimento & ou \\
Passo 1C - Provocar questionamento & ou \\
Passo 1D - Continuar a tradição & \\
MOVIMENTO 3: OCUPAR O NICHO & \\
Passo 1A - Delinear os objetivos & ou \\
Passo 1B - Apresentar a pesquisa & \\
Passo 2 - Apresentar os principais resultados & \\
Passo 3 - Indicar a estrutura do artigo & \\
\hline
\end{tabular}

Fonte: Swales (1990, p. 141, tradução por MOTTA-ROTH; HENDGES, 2010, p. 83)

Swales (1990) encontrou, portanto, a recorrência de três movimentos e onze passos retóricos na composição da Introdução dos artigos acadêmicos de seu corpus. O autor compreendeu "movimentos retóricos" (moves) como informações presentes no gênero que recorrem na maior parte de seus exemplares, à medida que "passos" (steps) seriam unidades informacionais menores e constituintes dos movimentos. Ao longo do tempo, tais conceitos foram sendo refinados e redesenhados pelo próprio teórico, mas, também, por outros pesquisadores.

Para Swales (2004), por exemplo, movimento é uma unidade discursiva ou retórica que exerce função comunicativa coerente no discurso falado ou escrito. Já Nwogu (1997, p. 122, tradução nossa ${ }^{3}$ ) vê o movimento retórico como um "segmento de texto composto por um conjunto de características linguísticas (significado lexical, significados proposicionais, forças ilocucionárias etc.)" que funcionam para cumprir os propósitos interacionais instanciados no e pelo gênero e os passos como elementos constituintes dos movimentos. Ainda que sejam elementos constituintes, concordamos com Yang e Allison (2003) quando destacam que um movimento pode ser realizado por apenas um passo retórico ou uma associação deles, assim como acrescentamos que, nas situações em que o movimento é construído por

3. "[...] text segment made up of a bundle of linguistic features (lexical meaning, propositional meanings, illocutionary forces, etc.) which give the segment a uniform orientation and signal the content of discourse in it" (NWOGU, 1997, p. 122). 
apenas um passo cuja função retórica se confunde com a do próprio movimento, podemos optar por manter apenas a indicação do movimento.

Nesse sentido, é possível citar tanto pesquisas que também optam pela indicação somente do movimento retórico, nos casos em que movimentos são constituídos por apenas um passo, e pesquisas que indicam tanto movimento quanto passo, apesar da semelhança de funções. Pacheco (2016), por exemplo, ao propor uma descrição sociorretórica do gênero artigo acadêmico na área de Nutrição, opta por manter apenas a indicação do movimento retórico, como na seção de Conclusão, em que o autor apresenta os movimentos "Apresentando interpretações gerais dos achados de pesquisa" e "Indicando implicações práticas de pesquisa". Já Freitas (2018), para a seção de Considerações Finais em artigos acadêmicos da comunidade disciplinar de História, propõe a indicação de movimento e passo mesmo nos casos de semelhança de funções retóricas: movimento "Sumarizando a análise" constituído pelo único passo "Sumarizando a análise historiográfica realizada ao longo do artigo" e movimento "Apresentando posicionamento final do autor" formado apenas pelo passo "Apresentando posicionamento final do autor frente ao objeto analítico permeado ou não por debate historiográfico".

A partir da complexificação de conceitos tais como "movimento" e "passo", é possível dizer que o modelo de configuração composicional recorrente para a seção de Introdução do gênero artigo acadêmico proposto por Swales (1990), o Modelo CARS, é resultado de um conjunto de procedimentos metodológicos, tomado por muitas pesquisas em Análise de Gêneros, para a descrição de variados gêneros e em variados contextos (ou comunidades discursivas). Este é o motivo pelo qual optamos por fazer uma distinção terminológica: chamamos de MODELO CARS o resultado da descrição do corpus de introduções analisado por Swales (1990) e de METODOLOGIA CARS o conjunto de procedimentos metodológicos que Swales desenvolveu para a análise de gêneros a partir da identificação e da explicação da configuração composicional de unidades informacionais prototípicas em relação com os propósitos interacionais que caracterizam os gêneros (BERNARDINO; ABREU, 2018).

Entre as pesquisas que utilizaram a Metodologia CARS, teremos em Costa (2015), que descreveu todas as unidades retóricas do gênero artigo acadêmico experimental produzido na área de Linguística, outro instrumento de análise: seu modelo sociorretórico para a unidade de introdução de artigos na área de Linguística. Uma comparação entre a descrição de Swales (1990), em diversas áreas, e de Costa (2015), na área de Linguística, para a seção de introdução do artigo acadêmico, indica "que a caracterização retórica, provavelmente, sofrerá flutuações 
em diferentes áreas do conhecimento" (BERNARDINO, 2007, p. 41). Motta-Roth e Hendges (2010) corroboram essa percepção, quando dizem que "cada área tem uma cultura própria que se traduz em um objeto de estudo próprio", o que resulta em "modos particulares de construir objetivos e procedimentos, [...] maneiras de usar a linguagem" (p. 68). Em outras palavras, apesar de o gênero ser o mesmo, cada área disciplinar o realizará de maneira particular.

Askehave e Swales (2009), embora com o objetivo de (re)discutirem o conceito de "propósito comunicativo", chegam a propor um procedimento metodológico de análise contextual de gêneros textuais que demarca bem a preocupação dos autores face à percepção das variações disciplinares. No modelo de análise contextual, os autores propuseram seis etapas de análise: identificação da comunidade discursiva; identificação de seus valores, objetivos e condições materiais; descrição de seus ritmos de trabalho e horizontes de expectativas; do repertório de gêneros da comunidade; revisão dos propósitos comunicativos de tais gêneros; e reconhecimento de suas características textuais.

\section{Quadro 2. Procedimento sistemático de análise contextual}

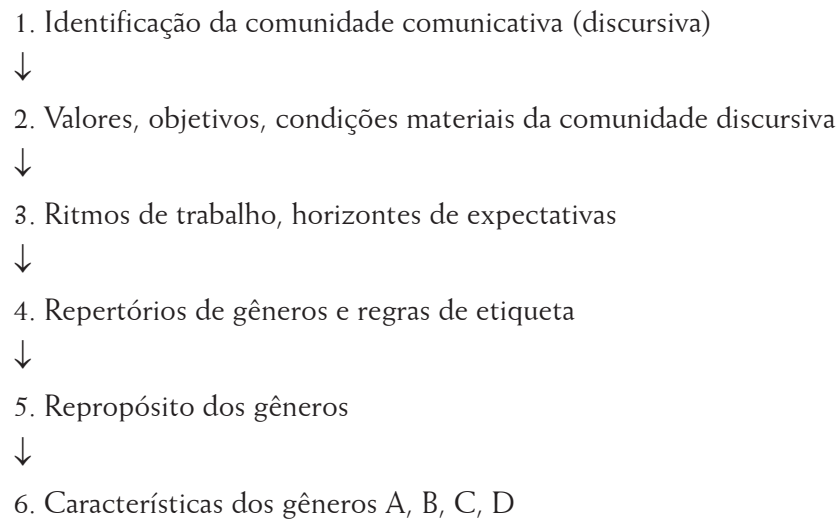

Fonte: Askehave; Swales (2009).

Se, por um lado, o reconhecimento da heterogeneidade que existe entre as áreas da comunidade científica contribui para que possamos compreendê-las melhor, ele também reitera as lacunas que existem em materiais didáticos de escrita acadêmica que ainda direcionam a produção de textos de modo generalizante ou demasiadamente técnico (Cf. PINHEIRO, 2016). Afinal, é por meio dos gêneros textuais que os integrantes de cada área compartilham teorias e descobertas relativas a sua própria comunidade disciplinar, com formas particulares de interação, procurando ser compreendidos e aceitos por seus pares. "Essa procura por aceitação 
é imprescindível na escolha de qual gênero usar, de que maneira construí-lo e de como fazê-lo circular" (BERNARDINO; VALENTIM, 2016, p. 124).

Ao mesmo tempo que a existência de variações disciplinares na realização de gêneros textuais reforça a importância de pesquisas que as levem em consideração no processo de análise, desafia bases teórico-metodológicas a lidarem com uma relação ainda mais densa entre gênero e contexto. Considerando isso, acrescentamos ao nosso aporte a noção de "cultura disciplinar", de Hyland (2000).

Para Hyland (2000), o discurso acadêmico, fundamental para a academia,

[...] não é uniforme nem monolítico, diferenciado apenas por especialistas e vocabulários. É o resultado de uma multiplicidade de práticas e estratégias [...]. Essas diferenças são, então, produto de forças institucionais e interacionais, resultado de diversas práticas sociais de escritores em seus campos (HYLAND, 2000, p. 3, tradução nossa ${ }^{4}$ ).

$\mathrm{O}$ autor percebe o discurso acadêmico e seus gêneros textuais, portanto, como espaços de interação e negociação entre pares de uma cultura disciplinar. A escrita, assim, é atravessada por práticas sociais e convenções anteriormente aprovadas pela comunidade acadêmica em foco. $\mathrm{O}$ estudo dessas interações, dessa forma, não é somente uma questão de perceber como escritores em diferentes disciplinas constroem conhecimento, mas, também, de revelar comportamentos sociais que foram sancionados por tais disciplinas, suas crenças epistêmicas e suas estruturas institucionais.

À medida que incorporam crenças e valores das instituições dentro das quais são produzidos, os discursos acadêmicos só podem ser compreendidos se forem compreendidos os aspectos disciplinares que os atravessam e os movimentos de negociação, construção e persuasão que realizam. Em nosso caso e nesse mesmo sentido, compreender a configuração composicional das introduções de artigos acadêmicos produzidos na cultura disciplinar da Linguística Aplicada só seria possível se fossem compreendidos, minimamente, os aspectos da disciplina que atravessam o gênero em estudo.

Para tanto, como veremos na seção a seguir, recorreremos a um terceiro instrumento de análise, o modelo analítico para análise sociorretórica de gêneros acadêmicos a partir da descrição de culturas disciplinares, proposto por Pacheco, Bernardino e Freitas (2018). Os autores, a partir do procedimento sistemático de análise contextual de Askehave e Swales (2009), desenharam uma proposta

4. "Scholarly discourse is not uniform and monolithic, differentiated merely by specialist topies and vocabularies. It is an outcome of a multitude of practices and strategies [...]. These differences are a product then of institutional and interactional forces, the result of diverse social practices of writers within their fields" (HYLAND, 2000, p. 3). 
metodológica que adicionou aspectos do conceito de cultura disciplinar, tais como o olhar de membros experientes, ao processo de análise sociorretórica de gêneros.

A seguir, descreveremos os procedimentos metodológicos escolhidos para a análise das 30 introduções de artigos acadêmicos experimentais de Linguística Aplicada.

\section{PERCURSO METODOLÓGICO}

Esta pesquisa é de natureza exploratório-descritiva, tem base qualitativa e quantitativa e se propõe a uma análise da seção de introdução de 30 artigos acadêmicos experimentais da área disciplinar da Linguística Aplicada (LA). As duas principais bases metodológicas para a análise foram o Modelo analítico para análise sociorretórica de gêneros acadêmicos a partir da descrição de culturas disciplinares (PACHECO, BERNARDINO; FREITAS, 2018) e a Metodologia CARS (SWALES, 1990). Enquanto a primeira delineou o percurso analítico da descrição da cultura disciplinar que permeia a área em questão, incluindo a etapa de descrição sociorretórica dos exemplares, a Metodologia CARS ocupou um lugar de grande importância enquanto modelo norteador para reconhecimento das unidades informacionais prototípicas caracterizadoras da configuração composicional das introduções. Dessa forma, nossa análise baseia-se numa perspectiva contextual, como sugerida por Askehave e Swales (2009), partindo da descrição do contexto em que o gênero emerge à descrição sociorretórica de exemplares de tal gênero.

A seguir, veremos o percurso metodológico proposto por Pacheco, Bernardino e Freitas (2018) para análise de gêneros a partir da descrição de culturas disciplinares. 
Quadro 3. Modelo analítico para a análise sociorretórica de gêneros acadêmicos a partir de culturas disciplinares

1 Identificando e compreendendo uma Cultura disciplinar

1.1 Compreendendo o conjunto de propósitos, de valores e de crenças da cultura disciplinar

\section{$\downarrow$}

1.2 Descrevendo processo de produção, de circulação e de consumo de gêneros acadêmicos

1.3 Descrevendo os propósitos comunicativos identificados pela cultura disciplinar para a realização do gênero investigado

2 Analisando amostra do corpus de exemplares do gênero investigado para orientar a construção dos questionários e das entrevistas utilizados para a investigação da visão dos membros experientes sobre o gênero

3 Revisitando a cultura disciplinar - Investigando como os membros experientes da cultura disciplinar reconhecem as unidades informacionais prototípicas dos gêneros e suas respectivas funções retóricas

4 Descrevendo sociorretoricamente unidades informacionais prototípicas a partir de um corpus do gênero à luz da descrição da cultura disciplinar.

Fonte: Pacheco, Bernardino e Freitas (2018, p. 126).

O percurso analítico apresentado propõe quatro etapas, partindo da identificação e da compreensão da cultura disciplinar que permeia dada área à descrição sociorretórica de exemplares do gênero produzidos no âmbito dessa cultura. Temos, em um primeiro momento, uma busca pela compreensão do conjunto de propósitos e valores que permeiam a área disciplinar elencada para análise, seguida da descrição do processo de produção, circulação e consumo de gêneros, até a descrição dos propósitos comunicativos identificados e suas estratégias de realização no e pelo gênero.

Em uma segunda etapa do percurso, dá-se a análise retórica preliminar de uma amostra do corpus que deve orientar a elaboração de questionários e/ou roteiro de entrevistas a serem aplicados a membros experientes da área. A terceira etapa compreende a aplicação de entrevistas e questionários que visem a identificação e a compreensão de funções retóricas das unidades informacionais prototípicas já identificadas na análise preliminar. A última etapa do percurso analítico aponta para a descrição e explicação (à luz das informações sobre a cultura disciplinar) sociorretórica integral das unidades informacionais prototípicas encontradas nos 
exemplares, tendo como principal ferramenta analítica a Metodologia CARS (SWALES, 1990).

Assim, nossas escolhas metodológicas apontam tanto para uma análise contextual em torno da produção de artigos acadêmicos em LA, à luz do conceito de Cultura Disciplinar (HYLAND, 2000), como para a descrição sociorretórica de exemplares do gênero textual artigo acadêmico produzidos na referida área, a fim de perceber a caracterização retórica prototípica da seção de Introdução desse gênero e sua relação com traços da cultura em que é realizado. Sendo assim, para além da descrição retórica de um corpus de 30 exemplares de introduções de artigos acadêmicos experimentais, lançamo-nos à aplicação de entrevistas a sete membros experientes da área disciplinar investigada, assumindo, como membros experientes, professores (a/s) pesquisadores (as) atuantes em programas de pós-graduação em Linguística Aplicada e/ou orientadores de grupos de pesquisas inseridos no âmbito da Linguística Aplicada, com frequência de publicação de artigos na área.

Esse procedimento nos levou a empreender uma descrição sociorretórica do gênero que levasse em conta, além de aspectos textuais, as vozes de integrantes de sua cultura disciplinar, aqueles que estão diretamente envolvidos na produção e na circulação do gênero em sua comunidade e que tendem a estar mais alinhados com os propósitos comunicativos do grupo. Neste sentido, os dados resultantes das entrevistas nos permitiram compreender melhor as funções retóricas das informações prototípicas encontradas na análise preliminar dos exemplares, assim como nos auxiliou na escolha das nomenclaturas de unidades retóricas que melhor refletissem as informações que se apresentaram no corpus.

Antes de passarmos à apresentação do modelo retórico de artigos acadêmicos de LA no qual resultou nossa pesquisa, discorreremos, de forma breve, sobre as etapas que o antecederam.

Primeiramente, realizamos uma busca pela identificação de revistas acadêmicas que recebem trabalhos de Linguística Aplicada com o maior estrato Qualis (Cf. BARATA, 2016) possível, selecionando, assim, três revistas A1: Revista Brasileira de Linguística Aplicada (RBLA); Revista Trabalhos em Linguística Aplicada (TLA) e Revista Documentação e Estudos em Linguística Teórica e Aplicada (DELTA). A partir de uma leitura exploratória de 100 resumos de artigos escolhidos aleatoriamente, nas duas primeiras revistas (que são específicas da área), publicados no intervalo de 2016 a 2018, verificamos os temas de pesquisa mais recorrentes que pudessem remeter à identificação de subáreas mais representativas da LA, por meio da análise de pistas textuais e das palavras-chave escolhidas pelos autores. Tomamos como referência, para a identificação de nomenclaturas das subáreas, nesta etapa, 
a tabela proposta pela Associação de Linguística Aplicada do Brasil (ALAB) em concordância com outras associações da grande área de Linguística e Literatura, formulada em 2006, que nos oferece um maior detalhamento da área, identificando subáreas mais representativas. O resultado dessa análise preliminar nos mostrou Ensino e Aprendizagem de Línguas (36\% das publicações), Alfabetização e Letramento (18\% das publicações), Formação de professores (14\%) e Linguagem e Práticas Sociais (13\%) como as especialidades mais representativas da LA.

Faz-se necessário ressalvar, no entanto, que não é nossa pretensão, neste estudo, promover qualquer análise comparativa entre estas subáreas. A busca pela identificação delas, neste primeiro momento, serviu unicamente ao propósito de assegurar, no momento de coleta do corpus, um equilíbrio entre as variáveis envolvidas na representação da área. Dessa forma, garantimos uma visão geral sobre as informações retóricas prototípicas que melhor caracterizam a escrita de artigos acadêmicos da área como um todo e não de suas subáreas individualmente.

Uma vez selecionados os periódicos dos quais retiraríamos o corpus para análise, fizemos um levantamento das orientações neles expressas, as quais entendemos como uma importante fonte de revelação dos propósitos e valores da área disciplinar bem como norteadoras dos processos de produção e circulação do gênero. Em seguida, coletamos os 30 exemplares que, para comporem o corpus, deveriam ser artigos experimentais (BERNARDINO, 2007), isto é, que tivessem como principal objetivo a apresentação/discussão de dados de qualquer natureza.

Compilados, os exemplares foram etiquetados como no exemplo "A1 LA", em que " $A$ " indica o gênero "artigo acadêmico", o numeral refere-se à identificação numérica do artigo (de 1 a 30) e "LA", à área de Linguística Aplicada. Registramos, na mesma compilação, outras informações importantes do corpus, como título do artigo, periódico do qual foi retirado, ano de publicação, número de autores, número de páginas e Qualis. Abaixo, para fins de exemplificação, o Quadro 4 mostra alguns desses registros. 
Quadro 4. Compilação e etiquetagem do corpus de análise

\begin{tabular}{|c|c|c|c|c|c|c|}
\hline $\begin{array}{c}\text { TíTULO DO } \\
\text { ARTIGO }\end{array}$ & $\begin{array}{c}\text { TÍTULO DO } \\
\text { PERIÓDICO }\end{array}$ & ANO & $\begin{array}{c}\mathrm{N}^{\circ} \text { DE } \\
\text { AUTORES }\end{array}$ & $\begin{array}{c}\mathrm{N}^{\circ} \text { DE } \\
\text { PÁGINAS }\end{array}$ & QUALIS & ETIQUETA \\
\hline $\begin{array}{c}\text { 1. Transtorno } \\
\text { de déficit de } \\
\text { atenção e } \\
\text { hiperatividade: } \\
\text { implicações } \\
\text { para a } \\
\begin{array}{c}\text { constituição } \\
\text { leitora do } \\
\text { aprendiz }\end{array}\end{array}$ & RBLA & 2016 & 01 & 25 & A1 & A1LA \\
\hline $\begin{array}{c}\text { 2. Professores } \\
\text { de Línguas e } \\
\text { programas do } \\
\text { livro didático }\end{array}$ & TLA & 2016 & 01 & 13 & A1 & A2LA \\
\hline $\begin{array}{c}\text { 3. Implicações } \\
\text { e problema- } \\
\text { tizações do } \\
\text { conceito de } \\
\text { Intersubjetividade: } \\
\text { um enfoque na } \\
\text { formação do } \\
\text { profissional de } \\
\text { línguas }\end{array}$ & RBLA & 2016 & O2 & 25 & A1 & A3LA \\
\hline
\end{tabular}

Fonte: nossa autoria.

O passo seguinte consistiu em identificar as unidades informacionais ocorrentes nas introduções dos 30 artigos, à luz da metodologia e do modelo CARS (SWALES, 1990), já apresentados na seção anterior, e do modelo apresentado por Costa (2015), a seguir, para a descrição da unidade de introdução em artigos acadêmicos experimentais da área da Linguística. 
Quadro 5. Descrição retórica da unidade de Introdução de artigos experimentais da cultura disciplinar da área de Linguística

$\begin{array}{ll}\text { Movimento 1: Apresentando o tema } & \\ \text { Passo 1 - Fazendo generalização/ões sobre o tópico } & \text { e/ou } \\ \text { Passo 2 - Estabelecendo a importância da pesquisa } & \text { e } \\ & \\ \text { Movimento 2: Apresentando a pesquisa } & \text { e/ou } \\ \text { Passo 1 - Apresentando objetivos } & \text { e/ou } \\ \text { Passo } 2 \text { - Apresentando aspecto(s) metodológico(s) } & \\ \text { Passo } 3 \text { - Indicando suporte teórico-metodológico } & \end{array}$

Fonte: Costa (2015)

A formulação do modelo de introduções apresentado por Costa (2015) para a área de Linguística baseou-se na Metodologia CARS e aponta para a existência de dois movimentos retóricos, Apresentando o tema e Apresentando a pesquisa como unidades informacionais prototípicas das introduções de artigos acadêmicos experimentais da área da Linguística, ambos realizados através de seus respectivos passos retóricos como demonstra o quadro acima.

Nesta etapa, empreendemos uma análise preliminar dos exemplares, o que levou ao surgimento de reflexões que nos possibilitaram elaborar de forma mais direcionada perguntas para serem aplicadas e solucionadas nas entrevistas semiestruturadas a sete membros experientes da área, realizadas em março de 2019. As perguntas versaram, dentre outras questões, sobre a construção retórica do gênero artigo acadêmico na área e a identidade do pesquisador em LA. Os entrevistados foram sete professores pesquisadores atuantes na área de Linguística Aplicada em dois programas de pós-graduação distintos: o Programa de PósGraduação em Linguística Aplicada da Universidade Estadual do Ceará (PosLAUECE) e o Programa de Pós-Graduação em Linguística da Universidade Federal do Ceará (PPGL- UFC). ${ }^{5} \mathrm{Na}$ análise, os entrevistados foram identificados pela sigla "ME" (Membro Experiente) seguida de identificação numérica (p. ex. ME03).

Após as entrevistas transcritas, selecionamos as principais informações referentes à seção de Introdução, retornamos ao corpus e iniciamos a descrição final dos exemplares das 30 introduções, a fim de perceber que unidades informacionais eram recorrentes. Seguindo Costa (2015), tomamos recorrência, aqui, como o aparecimento de dada unidade informacional em $50 \%$ ou mais do corpus. A análise

5. Todos os pesquisadores do Programa de Pós-Graduação em Linguística da UFC (PPGL-UFC) entrevistados eram professores atuantes na Linha de pesquisas em Linguística Aplicada (Linha 3). 
buscou, também, por pistas léxico-gramaticais que nos indicassem a presença de determinadas funções retóricas na realização do gênero, em diálogo constante com os dados das entrevistas que nos ajudassem a compreender a realização dessas funções.

Nas etapas apontadas acima, a aplicação da metodologia proposta por Pacheco, Bernardino e Freitas (2018) se mostrou fundamental para o entendimento da configuração prototípica do gênero. Nesse sentido, partimos de uma pesquisa inicial sobre a área para identificar propósitos que estariam subjacentes à produção do gênero, bem como das orientações sobre produção e circulação de artigos acadêmicos, presentes nos periódicos. Na sequência, fizemos uma análise preliminar dos exemplares que nos possibilitou uma visão geral da configuração retórica e nos deu informações que embasaram a aplicação de entrevistas a membros experientes. Em consonância com as observações feitas pelos membros experientes da área, finalizamos a análise sociorretórica dos exemplares, chegando a uma configuração retórica prototípica que apresentaremos e discutiremos na seção de análise. Saber, então, como a LA constrói a seção de Introdução em seus artigos e que propósitos estão por trás desse processo foram os questionamentos que guiaram nossa incursão metodológica na presente pesquisa.

A seguir, apresentamos e discutimos nossos resultados, a partir da apresentação da proposta de configuração sociorretórica construída a partir de nossa análise.

\section{RESULTADOS E DISCUSSÃO}

A descrição das unidades informacionais de nosso corpus foi feita a partir dos modelos de configuração retórica propostos por Swales (1990) e Costa (2015) e revelou a realização de movimentos e passos retóricos previstos e não previstos pelos dois pesquisadores. Portanto, apresentamos, inicialmente, o registro percentual da presença/ausência de informações retóricas indicadas nos dois modelos e encontradas (ou não) em nosso corpus, tecendo breves considerações, para, em seguida, apresentarmos a descrição retórica proposta por nós para a seção de Introdução em artigos acadêmicos experimentais de Linguística Aplicada.

Vejamos, no quadro abaixo, a frequência de informações retóricas presentes em nosso corpus quando tomamos como referência o modelo CARS (SWALES, 1990). 
Quadro 6. Frequência de unidades informacionais em Introduções de artigos acadêmicos experimentais da Linguística Aplicada com base no modelo CARS

\begin{tabular}{lc} 
Movimento 1: Estabelecer o território & $20 \%$ \\
\hline \hline Passo 1 - Estabelecer a importância da pesquisa e/ou & $0 \%$ \\
\hline Passo 2 - Fazer generalização/ões quanto ao tópico e/ou & $83,33 \%$ \\
\hline Passo 3 - Revisar a literatura (pesquisas prévias) & $0 \%$ \\
\hline \hline Movimento 2: Estabelecer o nicho & $0 \%$ \\
\hline Passo 1A - Contra-argumentar ou & $0 \%$ \\
\hline Passo 1B - Indicar lacuna(s) no conhecimento ou & $0 \%$ \\
\hline Passo 1C - Provocar questionamento ou & \\
\hline \hline Passo 1D - Continuar a tradição & $80 \%$ \\
\hline \hline Movimento 3: Ocupar o nicho & $36,66 \%$ \\
\hline \hline Passo 1A - Delinear os objetivos ou & $6,66 \%$ \\
\hline \hline Passo 1B - Apresentar a pesquisa & $50 \%$ \\
\hline \hline Passo 3 - Indicar a estrutura do artigo &
\end{tabular}

Fonte: elaboração de nossa autoria com base nos movimentos e nos passos sugeridos por Swales (1990) $)^{6}$.

Como podemos observar no quadro acima, três das funções retóricas presentes no modelo CARS apareceram de forma recorrente em nosso corpus: os passos Revisar a literatura (Passo 3, Movimento 1), que se apresentou em 83,33\% do corpus; Delinear os objetivos (Passo 1A, Movimento 3), com uma frequência de $80 \%$; e Indicar estrutura do artigo (Passo 3, Movimento 3), que aparece em 50\% dos exemplares. Observamos, ainda, que nenhum passo do movimento 2 apresentado por Swales (1990) foi verificado em nosso corpus.

No quadro a seguir, podemos ver a frequência de ocorrência e/ou recorrência das unidades informacionais do modelo retórico de Costa (2015), construído a partir de artigos experimentais da área de Linguística, em nosso corpus, de Linguística Aplicada. 
Quadro 7. Frequência de unidades informacionais em Introduções de artigos acadêmicos experimentais da Linguística Aplicada com base no modelo de Costa (2015)

Movimento 1: Apresentando o tema

Passo 1 - Fazendo generalização/ões sobre o tópico e/ou $0 \%$

Passo 2 - Estabelecendo a importância da pesquisa e $20 \%$

Movimento 2: Apresentando a pesquisa

Passo 1 - Apresentando objetivos e/ou $\quad 80 \%$

Passo 2 - Apresentando aspecto(s) metodológico(s) e/ou $26,66 \%$

Passo 3 - Indicando suporte teórico-metodológico $33,33 \%$

Fonte: elaboração de nossa autoria com base nos movimentos e passos sugeridos por Costa (2015).

Apesar de termos identificado, em nosso corpus, quatro dos cinco passos apresentados por Costa (2015), apenas um se mostrou recorrente durante a análise (Passo 1 do Movimento 2, Apresentando objetivos). Tanto o modelo CARS quanto o modelo de descrição retórica para Introduções proposto por Costa (2015) serviram, então, como referência para a identificação de unidades informacionais presentes nas 30 introduções de artigos acadêmicos experimentais de Linguística Aplicada. No entanto, para além das unidades informacionais dos dois modelos que recorreram nos exemplares analisados, nossa descrição identificou a presença de outras unidades não previstas por Swales (1990) e Costa (2015), culminando em um modelo retórico que nos permitiu visualizar como escritores da área disciplinar da Linguística Aplicada costumam apresentar as introduções de seus artigos.

Assim, apresentamos o quadro de unidades recorrentes na análise, com base em Swales (1990), Costa (2015) e nas unidades informacionais que se apresentaram para além desses modelos. Para a denominação terminológica das unidades não previstas nos modelos tomados como referência, partimos dos dados das entrevistas com membros experientes da área, assim como para posterior descrição e explicação da função de tais unidades retóricas. Tal escolha reafirma nosso compromisso com a proposição de uma análise sociorretórica de gêneros acadêmicos que considera não apenas a análise de aspectos textuais e retóricos, mas, também, as escolhas feitas por pesquisadores da área ao produzirem o gênero.

Vejamos, então, todas as informações retóricas recorrentes no corpus seguidas da indicação de frequência com que ocorreram nos 30 exemplares. 
Quadro 8. Unidades informacionais recorrentes em introduções de artigos acadêmicos experimentais da Linguística aplicada.

\begin{tabular}{|l|c|}
\hline \multicolumn{1}{|c|}{ Unidades retóricas recorrentes } & Recorrência \\
\hline $\begin{array}{l}\text { Construindo problematização por meio de contextualização sócio-histórica do } \\
\text { objeto }\end{array}$ & $83,33 \%$ \\
\hline $\begin{array}{l}\text { Construindo problematização em torno do objeto por meio de discussão com } \\
\text { literatura prévia }\end{array}$ & $83,33 \%$ \\
\hline Apresentando objetivos & $80 \%$ \\
\hline Apresentando objeto de pesquisa & $100 \%$ \\
\hline Indicando a estrutura do Artigo & $50 \%$ \\
\hline
\end{tabular}

Fonte: nossa autoria.

O quadro acima permite uma melhor visualização, em termos percentuais, da frequência das unidades informacionais que compõem nossa proposta de configuração retórica, registrando, também, a ordem em que ocorrem mais frequentemente em nosso corpus. Vejamos, portanto, no quadro abaixo, a descrição sociorretórica da seção de introdução em artigos acadêmicos da Linguística Aplicada.

Quadro 9. Descrição sociorretórica da unidade de Introdução de Artigos acadêmicos de Linguística Aplicada

Movimento 1- Construindo o objeto de pesquisa

Passo 1- Construindo problematização por meio de contextualização sócio-histórica do objeto

Passo 2- Construindo problematização em torno do objeto por meio de discussão com literatura prévia

Passo 3-Apresentando objetivos

Passo 4-Apresentando objeto de pesquisa

Movimento 2- Indicando a estrutura do artigo

Fonte: nossa autoria.

É importante pontuar que todas as denominações terminológicas dos movimentos e dos passos retóricos foram adaptadas, assim como fizeram BiasiRodrigues (1998) e Costa (2015), utilizando o verbo no gerúndio e não no infinitivo, por entendermos a realização de uma função retórica como uma construção, um movimento, um processo em andamento.

A descrição acima apresentada mostra a configuração sociorretórica prototípica resultante da análise de 30 introduções de artigos acadêmicos 
experimentais inscritos no escopo da Linguística Aplicada. Tal proposta, portanto, fundamenta-se na descrição de um corpus para apresentar o que é recorrente, sem pretensão de ser prescritivista e sem pretensão de configurar um manual, ainda que uma de suas possíveis contribuições seja oferecer um recurso didático a estudantes e pesquisadores quanto à escrita de artigos acadêmicos em determinada área. Passemos, então, à explicação sociorretórica da configuração composicional prototípica da Introdução de artigos acadêmicos experimentais da área disciplinar da Linguística Aplicada.

A configuração retórica apresentada, como podemos ver, possui dois movimentos retóricos: o Movimento 1 - Construindo o objeto de pesquisa e o Movimento 2 - Indicando a estrutura do artigo. O movimento 1 é realizado por meio de quatro passos: Construindo problematização por meio de contextualização sócio-bistórica do objeto $(83,33 \%$ de ocorrência); Construindo problematização em torno do objeto por meio de discussão com literatura prévia (83,33\% de ocorrência); Apresentando objetivos (80\% de ocorrência); e Apresentando objeto de pesquisa (100\%). Já o Movimento 2 - Indicando a estrutura do artigo ocorre em 50\% do corpus.

A construção do objeto de pesquisa (Movimento 1) se mostrou como a grande protagonista das introduções de artigos em LA, uma vez que se utiliza de quatro passos retóricos para a sua realização e ocupa quase toda a extensão do bloco textual das introduções dos exemplares analisados. Isto pode ser justificado pelo lugar de destaque que o objeto de pesquisa ocupa entre pesquisadores da área. Dos sete membros experientes entrevistados, cinco se referem, de forma explícita, à construção do objeto de pesquisa na seção de introdução dos artigos, como se lê nos seguintes excertos das falas de dois dos entrevistados: "Na introdução, eu construo o objeto de pesquisa" (ME05) e "É muito difícil construir o objeto de pesquisa, eu diria que bá duas dificuldades. A dificuldade intelectual e a dificuldade retórica de construção desse objeto" (ME06) ${ }^{7}$.

Deste modo, a escolha das nomenclaturas empregadas para os passos do Movimento 1 que se apresentaram como unidades informacionais não previstas nos modelos de Swales (1990) e de Costa (2015), foi motivada por pistas léxicogramaticais presentes nos textos em análise e confirmada pelas pistas léxicogramaticais presentes nas transcrições das entrevistas. Destacamos, ainda sobre o objeto de pesquisa, que, embora não se tenha um conceito fechado sobre ele, segundo

7. A transcrição das respostas às entrevistas foi adequada à norma padrão, com a retirada de marcas da oralidade, uma vez que a participação de membros experientes da área atende a um propósito sociorretórico e não sociolinguístico. Vale ressaltar também que, considerando os limites de extensão deste artigo, optamos pela apresentação de excertos das entrevistas que representam o panorama geral das respostas, tanto para a expressão de pontos comuns como para a exposição de divergências. 
um dos membros experientes entrevistados (ME06), algumas características o identificam, tais como, por exemplo, o fato de ser construído a partir da derivação de um fenômeno social e resultar do processo de elaboração do universo reificado da ciência, como também aponta Sá (1998).

Para exemplificarmos o Movimento 1, destacamos alguns excertos do corpus que confirmam a presença dos quatro passos retóricos que o realizam, discutindo-os a partir das entrevistas que apontam para a existência destas unidades informacionais na seção de Introdução e dos destaques de pistas léxico-gramaticais (por meio de grifos nossos). Vejamos, primeiramente, excertos referentes ao Passo 1 - Construindo problematização por meio da contextualização sócio-bistórica do objeto.

(01) No ano de 2011, pela primeira vez, depois de 11 anos da implementação do PNLD, é que a língua inglesa passon a fazer parte do Programa e livros didáticos (LD) de inglês foram selecionados e enviados às escolas públicas a fim de que os professores escolhessem com qual material desejariam trabalhar. (A2LA)

(2) Uma das características marcantes do cenário educacional brasileiro nesse momento é a forte presença de avaliações para todos os níveis de ensino: Provinha Brasil, Prova Brasil, ENEM, ENADE, PISA, além das provas específicas dos estados e municípios. (A9LA)

(3) A pluralidade de usos da linguagem, em diferentes contextos sociais, tem estimulado estudiosos da educação e da linguagem a desenvolverem pesquisas para entender o uso das novas práticas de linguagem na formação dos aprendizes. (A25LA)

Como podemos observar, a unidade informacional Construindo problematização por meio de contextualização sócio-bistórica do objeto tem a função retórica principal de preparar o leitor para a apresentação do objeto de pesquisa, fazendo-o a partir da construção do cenário histórico e social no qual o objeto pode ser tomado para investigação. Em alguns dos excertos, é possível perceber pistas que apontam para localizações temporais, espaciais e socioculturais nessa problematização, como em "Uma das características marcantes do cenário educacional brasileiro nesse momento [...]" (02) ou em "A pluralidade de usos da linguagem, em diferentes contextos sociais, tem estimulado estudiosos da educação e da linguagem [...]" (03). Quanto às entrevistas, podemos observar a confirmação da presença deste passo retórico em declarações como "A Introdução, para mim, é a contextualização [...], você precisa situar o objeto que você vai apresentar, é uma contextualização" (ME04, grifo nosso) ou ainda em "Eu vejo que a gente já começa [a] suscitar o problema de pesquisa na introdução, né?! A gente já prepara o leitor para o problema de pesquisa e dá ali o contexto" (ME03, grifo nosso). 
Pontuamos que, apesar do passo retórico 1, observado em nossa descrição, guardar semelhanças com o passo "Fazendo generalizações sobre o tópico", do modelo proposto por Costa (2015), não os tomamos como equivalentes, pois consideramos que desempenham funções retóricas distintas. Enquanto "Fazer generalizações sobre o tópico" aparece em Costa (2015) como um passo que realiza um movimento denominado "Apresentando o tema", a "Construção de problematização por meio de contextualização sócio-histórica do objeto" é um dos passos que realiza o movimento retórico de construção do objeto de pesquisa, que se configura como uma função retórica que vai além da apresentação da temática do artigo, antecedendo a apresentação do objeto de pesquisa, que entendemos como distinto do tema.

Para o Passo 2 - Construindo problematização em torno do objeto por meio de discussão com literatura prévia, apresentamos, como exemplos, os seguintes excertos:

(4) Nessa abordagem de parceria, Knight $(2007,2009)$ propõe que o coach se utilize de um conjunto de sete princípios, que às vezes se sobrepõem, para estabelecer uma relação colaborativa e exitosa com o professor. (A23LA)

(5) De acordo com Bourdieu e Passeron (2009), o sistema educacional e escolar é responsável por manter muitas das desigualdades da sociedade, perpetuando e reproduzindo discursos e relações que legitimam as diferenças sociais fora das salas de aula. (A26LA)

Para esclarecer como a função retórica de construção de problematização em torno do objeto por meio de discussão com literatura prévia está sendo construída nos excertos dos exemplares A23LA e A26LA, explicitamos que, no primeiro exemplar, o objeto de pesquisa gira em torno de "um caso de formação continuada via coaching instrucional realizado no Brasil, ancorado na abordagem da parceria proposta por Knight". (A23LA) e, no segundo exemplar, a questão é sobre como a "identidade de classe social deve se tornar um aspecto relevante a ser considerado e investigado no ensino- aprendizagem de línguas" (A26LA) ${ }^{8}$

$\mathrm{O}$ passo aqui discutido tem como função retórica o estabelecimento do diálogo entre literatura prévia e o objeto de investigação dos artigos. Parece-nos que os autores de artigos experimentais em LA buscam justificar o preenchimento de uma lacuna de investigação para a construção do objeto, mostrando pesquisas anteriores em torno da temática próxima ao objeto pretendido. Como podemos perceber na voz de um dos entrevistados:

8. Os excertos aqui apresentados foram inseridos a fim de explicitar a relação entre a discussão com literatura prévia e a construção do objeto no corpus analisado. 
a Introdução, o que não pode faltar tem variações dependendo das culturas disciplinares, mas tem que ter o problema, o objetivo da pesquisa e a relevância. Essa relevância é construída [...] com base em outros trabalhos, ela vai trazer outros trabalhos, chamado de estado da arte também, outros trabalhos para dizer como está aquela temática. Ele vai mostrar como o trabalho dele se diferencia de outros trabalhos que que têm uma temática relacionada diretamente ou indiretamente ao dele, aí é que ele constrói a relevância da pesquisa. (ME07, grifo nosso)

Essa unidade informacional foi verificada em $83,33 \%$ dos exemplares, o que nos leva a concluir que os membros da área constroem seus objetos de investigação também por meio do diálogo com pesquisas prévias em torno do objeto. Passemos à descrição do terceiro passo retórico que realiza o movimento 1.

O passo retórico Apresentando objetivos ocorre em $80 \%$ do corpus analisado, indicando que pesquisadores de LA tendem a apresentar, na Introdução, o que pretendem com o trabalho publicado. É importante pontuar que, dos seis exemplares do corpus que não apresentaram este passo retórico na seção de introdução, quatro o apresentaram no resumo do artigo, dada a importância dessa unidade informacional na composição do artigo científico. Ainda quanto à presença desta unidade informacional na introdução, cabe destacar que ela também ocorre nos modelos que tomamos como referência, como passo retórico, recebendo a denominação "Delinear os objetivos", em Swales (1990), e "Apresentando objetivos", em Costa (2015).

Destacamos, a seguir, alguns excertos do corpus em que verificamos a presença deste passo.

(6) O presente trabalbo tem o objetivo de apresentar discussões relativas ao percurso histórico da criação de programas governamentais com o intuito de gerir a avaliação, a seleção e o envio de livros didáticos às escolas públicas brasileiras. (A2LA)

(7) Em face das questões empíricas e teóricas apontadas, o objetivo deste artigo é analisar a organização retórica da seção de justificativa do gênero pré-projeto de pesquisa, correlacionando-a aos modos de funcionamento do gênero, num corpus de projetos de mestrandos aprovados em processos seletivos na área de Linguística, numa universidade pública brasileira. (A13LA)

(8) Diante disso, este artigo procura trazer contribuições no que se refere à construção de uma semiologia do agir para a análise do agir docente.

Nos excertos acima, podemos identificar marcas léxico-gramaticais tanto explícitas, como em "o objetivo deste artigo é analisar" (07), como implícitas, em "este artigo procura..." (08), apontando ambas para a função retórica de apresentação do(s) 
objetivo(s) da pesquisa. É interessante observar que a presença desta unidade foi citada como imprescindível por seis dos sete entrevistados, em falas tais como: "a Introdução tem que já prender o leitor, o interessando. Então eu acho que você tem que trazer ali informações do tipo qual o objetivo daquele texto, a que eu me proponho naquele artigo" (ME01, grifo nosso) e "Na Introdução, no caso, lembrar de colocar objetivo, deixar muito claro o objetivo" (ME03, grifo nosso).

O passo Apresentando objeto de pesquisa foi verificado em todos os exemplares, aparecendo em $100 \%$ do corpus e tem como função retórica indicar ao leitor o objeto de investigação sobre o qual a pesquisa se debruça. Na ordem de configuração prototípica das informações retóricas dos exemplares, apareceu de forma mais recorrente logo após a apresentação dos objetivos da pesquisa, vindo conjugado com esse passo na maioria das vezes $(73,33 \%)$.

Nesse sentido, os seguintes excertos podem exemplificar a unidade informacional de apresentação do objeto de pesquisa em introduções de artigos da Linguística Aplicada:

(9) Este artigo tem como objeto a formação de profissionais na área da educação em linguagem, âmbito em que problematizamos o conceito de intersubjetividade tal qual proposto por Wertsch (1985) [...]. (A3LA)

(10) Nesse sentido, este artigo tem como principal objetivo relatar uma experiência de sala de aula de língua estrangeira com 18 (dezoito) alunos do $5^{0}$ semestre de Espanbol do Núcleo de Línguas da Universidade Estadual do Ceará (UECE), realizada com a leitura de um texto multimodal do livro didático de Lingua Espanbola adotado em sala de aula. (A25LA)

(11) Para tanto, apresentamos e discutimos categorias de modos de agir mobilizados durante o planejamento e a produção de uma sequência didática (SD) (Schneuwly, Dolz, 2004) para o ensino de Língua Inglesa (LI). (A19LA)

A exemplo do que aconteceu no passo anterior, a indicação de presença do passo Apresentando objeto de investigação aconteceu ora explícita ora implicitamente, conjugada com a apresentação de objetivos, como já pontuamos. Considerando que a frequência do passo Apresentando objetivos tenha sido de $80 \%$ no corpus, destacamos que apenas dois dos exemplares que apresentaram objetivos na Introdução não os apresentaram conjugados com a apresentação do objeto de pesquisa (a exemplo do excerto 09) e que, quando o apresentaram, a forma mais prototípica de ocorrência do objeto foi como um complemento de verbos indicativos da apresentação de objetivo (a exemplo do que ocorre nos excertos 10 e 11). 
Quanto às informações colhidas nas entrevistas que dialogaram com os dados encontrados na descrição retórica dos exemplares, destacamos a observação de uma das entrevistadas sobre a indicação do objeto já vir na Introdução e que "você precisa situar o objeto que você vai apresentar" (ME04, grifo nosso). Outro entrevistado, quanto ao mesmo ponto, afirmou que, "sintaticamente, o objeto vem marcado nem sempre vem, mas deveria vir - depois do verbo do objetivo geral" (ME06). Deste modo, é possível perceber a confirmação das informações encontradas por nós na análise textual quando contrastadas com a observação dos pesquisadores relativas ao Passo 4 - Movimento 1.

Destacamos, ainda sobre o Movimento 1, que a escolha da denominação Construindo o objeto de pesquisa se deu em parceria com os participantes da pesquisa, sendo uma das questões abordadas nas entrevistas. Ao identificarmos esta unidade informacional já na análise preliminar do corpus, resolvemos confirmá-la junto aos membros experientes da área que entrevistamos, questionando, em um primeiro momento, se eles identificavam a construção de uma problematização em torno do objeto de pesquisa nas introduções de artigos de LA, o que todos confirmaram. Em um segundo momento, perguntamos como eles compreendiam essa construção, momento das entrevistas que nos auxiliou na escolha da denominação Construindo objeto de pesquisa, como se pode ver na resposta de ME05: "Eu sempre defendo que o objeto de pesquisa não existe, ele é uma construção discursiva do pesquisador e essa construção discursiva está numa parte muito importante do artigo que eu chamo de Introdução".

Finalmente, observamos a recorrência do Movimento 2 - Indicando a estrutura do artigo em $50 \%$ do corpus. A função retórica deste movimento, segundo um dos membros experientes entrevistados, é "anunciar as partes que vêm depois" (ME04), vindo sempre no último parágrafo. Esta informação é confirmada pela própria estrutura léxico-gramatical das construções linguísticas verificadas nos exemplares em que a unidade informacional ocorre, como se pode ler nos exemplos abaixo:

(12) O artigo subdivide-se em três seções de conteúdo: na primeira delas, apresentamos o conceito de intersubjetividade com base em Wertsch (1985); na seção seguinte, propomos sua ressignificação a partir da articulação com o conceito de encontro; na terceira e última, à luz da proposta de ressignificação levada a termo ao longo do artigo, discutimos dados de campo correspondentes a um grupo de pesquisa na área da linguagem, os quais foram gerados por meio de notas em diário de orientação. (A3LA)

(13) Na intenção de apresentar ao leitor um breve retrospecto da metodologia Webquest, este trabalho está dividido em 3 seções, além desta introdução e das considerações finais: (1) Webquest: 
do passado ao presente; (2) O que é uma Webquest Interativa e Adaptável voltada ao ensino de línguas? e (3) Reflexões de professores em formação sobre o uso de Webquests Interativas e Adaptáveis nas aulas de língua inglesa. (A27LA)

Conforme apontam Yang e Allison (2003), quando destacam que um movimento pode ser realizado por apenas um passo retórico ou uma associação deles, consideramos que em situações nas quais um movimento é realizado por um único passo que se funde à função retórica do próprio movimento ou com ela se confunde, não se faz necessária a indicação explícita do passo, podendo optar o analista por manter apenas a indicação do movimento, conforme fazemos neste artigo.

A partir da discussão dos resultados desta análise sociorretórica de 30 exemplares de introduções de artigos experimentais da LA, podemos inferir que pesquisadores de Linguística Aplicada, ao produzirem artigos acadêmicos, apresentam uma forma particular de publicizar suas pesquisas, alinhando propósitos comunicativos da área a uma configuração retórica prototípica do gênero. Desta forma, valem-se da seção de Introdução para construir o objeto de pesquisa, sendo este o grande protagonista da seção, e o fazem partindo de uma contextualização sóciohistórica do objeto, passando pela construção de uma problematização em torno dele, por meio de discussão com literatura prévia e pela apresentação de objetivos, culminando, assim, em sua apresentação propriamente dita.

Observamos, ainda, que a seção de introdução de artigos de LA costuma apresentar, no último parágrafo, um panorama do que virá a seguir, apontando para a configuração das seções seguintes, com o intuito de antecipar brevemente ao leitor a organização retórica do texto.

\section{CONSIDERAÇÕES FINAIS}

Embora não possamos tomar nossas conclusões como fechadas, dada a possibilidade de um estudo futuro que tome como análise um número maior de exemplares, o que poderia trazer a identificação de novas unidades informacionais, entendemos que, ao analisarmos 30 exemplares de introduções de artigos experimentais de LA, foi possível traçar uma descrição sociorretórica aproximada da configuração prototípica do gênero produzido no âmbito da área disciplinar em estudo.

O modelo de configuração sociorretórica que propomos se apresenta, então, como uma referência para pesquisadores da LA que desejam compor artigos para 
publicação de suas pesquisas, publicizando seus trabalhos e, assim, dialogando com outros pesquisadores da área. Nesse sentido, entendemos que quanto maior a apropriação consciente dos mecanismos retóricos envolvidos na escrita do gênero, alinhados com os propósitos comunicativos da cultura disciplinar que permeiam a área, maior a probabilidade de um pesquisador ser reconhecido como membro autorizado no âmbito de sua comunidade acadêmica.

Outro impacto relevante de nossos resultados diz respeito à contribuição para a escrita de membros iniciantes da academia, pois favorece o ensino explícito de gêneros acadêmicos. A apropriação da configuração sociorretórica prototípica dos gêneros acadêmicos auxilia a compreensão dos propósitos e dos mecanismos envolvidos na escrita, proporcionando caminhos para o empoderamento e o pertencimento às comunidades disciplinares.

\section{$\overline{\text { REFERÊNCIAS }}$}

ABREU, N. O. (2016). O artigo acadêmico na cultura disciplinar da área de Psicologia: um estudo sociorretórico. Dissertação de Mestrado em Linguística Aplicada. Centro de Humanidades, Universidade Estadual do Ceará, Fortaleza.

ASKEHAVE, I.; SWALES, J. M. (2009). Identificação de gênero e propósito comunicativo: um problema e uma possível solução. In: BEZERRA, B. G.; BIASI-RODRIGUES, B.; CAVALCANTE, M. M. (org.). Gêneros e sequências textuais. Recife: Edupe. p. 221-247.

BARATA, R. C. B. (2016). Dez coisas que você deveria saber sobre o Qualis. Revista Brasileira de Pós-Graduação, v. 13, n. 1, Brasília, jan./abr.

BERNARDINO, C. G. (2000). Depoimento dos alcoólicos anônimos: um estudo do gênero textual. Dissertação de Mestrado em Linguística. Universidade Federal do Ceará, Fortaleza.

BERNARDINO, C. G. (2007). O metadiscurso interpessoal em artigos acadêmicos: Espaço de negociações e construção de posicionamentos. Tese de Doutorado em Linguística Aplicada. Universidade Federal de Minas Gerais, Belo Horizonte.

BERNARDINO, C. G.; VALENTIM, D. L. (2016). O gênero artigo acadêmico e a cultura disciplinar da área do Direito: as primícias de uma análise sociorretórica. Revista Virtual de Letras, Jataí, v. 8, n. 2, p. 122-141, ago./dez.

BERNARDINO, C. G.; ABREU, N. O. (2018) A unidade retórica de Metodologia em artigos empíricos da cultura disciplinar da área de Psicologia: uma investigação 
sociorretórica. Revista Brasileira de Linguística Aplicada, Belo Horizonte, v. 18, n. 4, p. 887-918.

BIASI-RODRIGUES, B. (1998). Estratégias de condução de informações em resumos de dissertações. Tese de Doutorado em Letras/Linguística. Universidade Federal de Santa Catarina, Florianópolis.

BIASI-RODRIGUES, B.; HEMAIS, B.; ARAÚJO, J.C. (2009). In: BIASI-RODRIGUES, B.; ARAÚUO, J.C.; SOUSA, S.C.T. (Org). Gêneros textuais e comunidades discursivas: um diálogo com John Swales. Belo Horizonte: Autêntica Editora. p. 17-32.

COSTA, R. L.S. (2015). Culturas disciplinares e artigos acadêmicos experimentais: um estudo comparativo da descrição sociorretórica. Dissertação de Mestrado em Linguística Aplicada. Centro de Humanidades, Universidade Estadual do Ceará, Fortaleza.

FREITAS, T. L. (2018). O Artigo Acadêmico na cultura disciplinar da área de História: uma investigação sociorretórica. Dissertação de Mestrado em Linguística Aplicada. Centro de Humanidades, Universidade Estadual do Ceará, Fortaleza.

HYLAND, K. (2000). Disciplinary discourse: social interactions in academic writing. Singapura: Pearson Education Limited.

LIM, J. M. H. (2006). Method sections of Management research articles: a pedagogically motivated qualitative study. English for Specific Purposes, v. 25, p. 282-309.

LIMA, L. O. B. (2015). Práticas discursivas em comunidades disciplinares acadêmicas: a construção do posicionamento em artigos experimentais das áreas de Medicina e Linguística. Dissertação de Mestrado em Linguística Aplicada. Centro de Humanidades, Universidade Estadual do Ceará, Fortaleza.

MOTTA-ROTH, D. (Org.). (2002). Redação acadêmica: princípios básicos. Santa Maria: Universidade Federal de Santa Maria, Imprensa Universitária.

MOTTA-ROTH, D. ; HENDGES, G. R. (2010). Produção textual na universidade. São Paulo: Parábola Editorial.

NWOGU, K. N. (1997). The Medical research paper: structure and functions. English for Specific Purposes, v. 16, n. 2, p. 119-138.

PACHECO, J. T. S. (2016). O artigo acadêmico na cultura disciplinar da área de Nutrição: uma investigação sociorretórica. Dissertação de Mestrado em Linguística Aplicada. Centro de Humanidades, Universidade Estadual do Ceará, Fortaleza. 
PACHECO, J. T. S. ; BERNARDINO, C. G.; FREITAS, T. L. (2018). Um estudo sociorretórico da seção de Conclusão em artigos originais da cultura disciplinar da área de Nutrição. Entrepalavras, Fortaleza, v.8, n.1, jan./abr.

PINHEIRO, M. V. B. L. (2016). Uma análise do gênero artigo acadêmico em manuais de orientação da escrita científica. Dissertação de Mestrado em Linguística Aplicada. Centro de Humanidades, Universidade Estadual do Ceará, Fortaleza.

SÁ, C. P. (1998). A construção do objeto de pesquisa em representações sociais. Rio de Janeiro: EDUERJ.

SILVA, L. F. (1999). Análise de gênero: uma investigação da seção de Resultados e Discussão em artigos científicos de Química. Dissertação de Mestrado em Letras. Universidade Federal de Santa Maria, Santa Maria.

SWALES, J. M. (1990). Genre analysis: English in academic and research settings. Cambridge: University Press.

SWALES, J. M. (2004). Research genres: explorations and applications. New York: Cambridge University Press.

YANG, R.; ALLISON, D. (2003). Research articles in Applied Linguistics: moving from Results to Conclusions. English for Specific Purposes, v. 22, p. 365-385.

Recebido: 4/06/2019

Aceito: 13/10/2019

Publicado: 13/01/2020 